\title{
Understanding ELT Academics' Teaching Methods in the United States: A Qualitative Study ${ }^{1}$
}

\author{
Ceyhun Yükselir \\ Osmaniye Korkut Ata University
}

\begin{abstract}
:
While much research delineates teaching methods for second language in English Language Teaching (ELT) field, few studies were conducted in the United States (US) context. Thus, the current study examines ELT academics' teaching methods within the context of the US higher education. In this qualitative study, online semi-structured interviews, reflections and classroom observations were used to collect qualitative data from a sample group of 17 participants working in two US higher education institutions. The data were analyzed separately using content analysis. The results indicated that lecturers employ inquiry-based teaching and communicative teaching approaches enriched with technological facilities in their classrooms thereby enabling learners to improve productive and creative/critical thinking skills. To this end, it is recommended that ELT teachers and lecturers should create second a language learning environment in which topics regarding culture and real-life context are integrated into their teaching. Furthermore, this study also suggests that researchers do more study regarding teaching methods in ELT for future research.
\end{abstract}

Keywords: Teaching Methods, English Language Teaching (ELT), United States (US) Higher Education, Qualitative Study

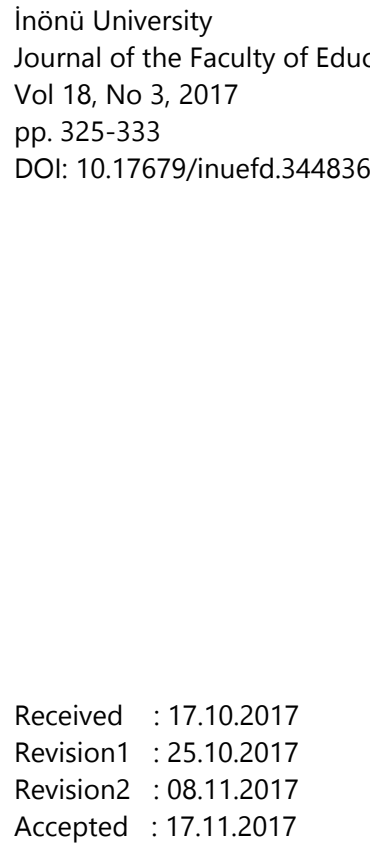

\section{Suggested Citation}

Yükselir, C. (2017). Understanding ELT Academics' Teaching Methods in the United States: A Qualitative Study, Inonu University Journal of the Faculty of Education, 18(3), 325-333. DOI: 10.17679/inuefd.344836

\footnotetext{
${ }^{1}$ This study was supported by the Scientific and Technological Council of Turkey within International Post-Doctoral Fellowship Program
} 


\section{INTRODUCTION}

There has been a tremendous growth of research in the field of the English language teaching (ELT) over the years and still remains its importance. As Giri (2016) claims that ever-changing teaching learning methods which meet the demands and needs of the 21st century skills can have an effect in all paces of education on comparing the past teaching learning experiences. Karn (2007) also mentioned that language teaching in its broadest sense and ELT in particular has changed over the centuries. Simply put, what's the best way to teach English from children to adults who aren't native speakers using English as their second language? This research deals with English language teaching methods within the United States (US) higher education system, in which how English language learners (ELLs) who enrolled at the university learned a foreign language. Before giving the research questions, it is more appropriate to mention about the meaning and usage of 'method'. According to Richards and Rodgers (2003), "method is the level at which theory is put into practice and at which choices are made about the particular skills to be taught, the content to be taught, and the order in which the content will be presented" (p. 21). What makes this study important is that it tries to find English teaching methods in its real context and attempts to provide the latest methods for the teachers as well. After this introduction, the following research questions were formed in line with the purpose of the study:

1. What are the main methods lecturers use while teaching a second language?

2. What materials are most commonly used by lecturers in US higher education?

3. What do lecturers think about the current status of second language teaching in US higher education system?

This section introduces and outlines the research, and it also provides insights about the purpose of the study.

\section{LITERATURE REVIEW}

Upon considering the methods regarding second language teaching, it can be difficult to find a concrete one due to the changing needs of the learners just as the needs of the country's cultural, social and economic expectations changed. Briguglio and Watson (2014) claim that teaching English language as a second or additional language should be revised and reconsidered by means of student initiative and submersion into the process of teaching and learning. Devlin and Samarawicklevra (2010) put forward that the quality of higher education teaching and learning is related to the shared understandings of teaching, which requires incorporating skills and teaching activities with a wide range of multiple contexts. According to Eaton (2010) the criteria of effective teaching in a changing higher education context is more learnercentered, more collaborative and more technologically driven. Hannan and Silver (2000) also show that technological changes are linked with effective teaching methods in higher education. In relation to this, Eaton (2010) also suggests that the use of technologies can be carried out in real time synchronically such as Skype, Moodle or virtual live classes; or they may be vice versa (not carried out in real time) such as podcasts and blogs. Another striking technology called mobile assisted language learning (MALL) is one of the booming technologies and mobile phone "has evolved from a simple voice device to a multimedia communications tool capable of downloading and uploading text, data, audio, and video - from text messages to social network updates to breaking news, the latest hit song, or the latest viral video" and that it can also 'be used as a wallet, a compass, or a television, as well as an alarm clock, calculator, address book, newspaper, and camera" (Kelly and Minges, 2012, p. 11).

When compared the $20^{\text {th }}$ century methods to English language teaching, such as grammar-translation, direct method and audio-lingual method etc., today's changing world requires student portfolios, studentmade videos, student blogs, Wikis and podcasts etc. (Eaton, 2010). In the literature, it is widely acknowledged that there are two kinds of models of ELT in the world: English immersion, which is an instructional model only in English or bilingual education, an instructional model both in English and learner's native language (Slavin and Cheung, 2005). Taking the models into account, there are some prerequisites for putting them into action, such as preparation, comprehensible input, strategies, practices and assessment (Moughamian et al., 2009). These items can be added more in general. Regarding the first 
model, the use of English as a medium of instruction in higher education is gaining importance and getting grounded well particularly in non-English speaking countries because of the internationalization in the world (Coleman, 2006).

The next section gives the method, research context, participants, data collection and data analysis of the research.

\section{METHOD}

The current study involved online semi-structured interviews, reflections and classroom observations. Before carrying out the study, the significance and purpose of the study and methodological tools were explained to the participants and the consents were also taken showing that they voluntarily participated in the study. Then all of the participants were informed about the research process and its contributions to the field. The data collection tools of the current study consisted of, as mentioned above, online interviews, reflections and classroom observations. In order to obtain triangulation of the data, these three instruments were used in the current study. As it is widely known, as a validity procedure, "triangulation is a step taken by researchers employing only the researcher's lens, and it is a systematic process of sorting through the data to find common themes or categories by eliminating overlapping areas (Creswell and Miller, 1994, p. 127). In the online semi-structured interviews, reflections and classroom observations, the researcher asked the participants about their views on these topics:

the methods/approaches about second language teaching they taught

the teaching materials they used and their activities

the general opinion about the teaching system in US higher education, how they felt about the performances and how they overcome the problems in the classrooms

In other words, participants' personal opinions obtained from the online interviews, reflections and classroom observations were used to collect the data qualitatively.

In the current study, the researcher used a qualitative collective instrumental multiple case study design in order to explore the views of the ELT academics working in two universities. A case study is "an exploration of a 'bounded system' or a case (or multiple cases) over time through detailed, in-depth data collection involving multiple sources of information rich in context (Creswell, 1998, p. 61). In relation to this, Yin (2003) state that a multiple case study provides the researcher with the exploration of differences within and between cases so that some similar results can be predicted and drawn from the cases.

\section{Participants}

The sample group of the research consisted of 17 lecturers/instructors working at the two universities in the US. The rationale behind choosing these participants for this study was that all of the participants were experienced lecturers in second language teaching and had sufficient knowledge about US higher education system. Thirteen participants were female and four males. The researcher himself conducted 17 online interviews with the people working in two universities and interviewed 3 participants out of 17 twice to obtain more views and perceptions. Before interviewing them, the researcher tried to know them by meeting, making an appointment and exchanging emails casually thereby enabling them to feel comfort in the interview. According to Roulston (2010), this kind of interviewing means that "the burden of proof for establishing quality has shifted from showing both the participants and researchers to be reliable and accurate witnesses, to emphasize the researcher's accounts of his/her place within the research process (in the generation of data, research design, and analysis, interpretation and representation of findings), and relationship to the participants of the study" (p. 218).

\section{Research Context}

As a way to understand the language teaching pedagogy within the context of US higher education system, the researcher visited two universities in the US as a visiting scholar in 2017 and had some intimate connections with the scholars working there. The researcher had already some notes and after coming back, also arranged online conversations through internet. The settings were all about English language teaching departments. In this context, the researcher also visited Graduate School of Education and 
conducted informal conversations with the administrators who are in charge of the teaching system/curriculum, lecturers/instructors and students as well. In fact, these two universities have not the same tendencies towards teaching methods, and this can be due to the fact that most universities in the US are decentralized, which means they are not connected to one unique system. Each university or even each institution has its own system. There is a different kind of language teaching system in the one of the target universities. First of all, it doesn't have any preparatory class for one year either optional or compulsory. In order to have the chance to study, each student took the minimum grade from the accredited exams, such as TOEFL and GRE. This stems from the fact that their native language English as a medium of instruction is offered to the students in any level of education. However, taking the second languages, Spanish and French, into account, there is not any preparatory class, either. They offer just language courses for different periods of time and within a course system. Secondly, the functionality of the Language Center is to meet with the students for the purpose of organizing conversation clubs, not teaching English or any other second languages in the classroom environment. This Center is trying to help students/scholars broaden their horizons regarding the language system and maintain the real context life via showing some videos or podcasts. It is not an undergraduate or a graduate program in which language courses are just organized for short or long-term periods of time. Lastly, there is a Teaching Program in Graduate School of Education offering $\mathrm{MA}$ and $\mathrm{PhD}$ courses with a range of eligible courses in the leadership of qualified academicians. This school is not directly preparing the language teaching curriculum for the institutions in the university.

In order to carry out this study, the researcher paid mininum 20 visits for almost 1-2 hours per visit to the English Language Center, the primary aim of which is to teach English for undergraduate and graduate students and Modern Languages and Cultures, in which ten foreign languages are taught through course system. The researcher also carried out online interviews, reflections and classroom observations with the colleagues teaching in English Language Center and mentioned about the research and directed to them online semi-structured interview questions of the study.

\section{Data Collection}

The data collection tools of the current study consisted of, as noted above, online semi-structured interviews, reflections and classroom observations.

In line with the research questions, the researcher used the following online semi-structured interview questions:

What kind of method do you use / employ in your class? Could you give information about it?

What kind of teaching materials do you usually use?

Do you prepare your testing materials or benefit from the ready-to-use test?

What's your point of view about the second language teaching in the existing American higher education system?

The researcher selected two universities in the same place based on the participants' willingness in order to share their language teaching experiences, observe and try to see the whole picture. Data collection process was carried out in 2017. These online interviews were recorded and lasted approximately 45-60 minutes in length per person. The researcher collected the data via online semi-structured interviews with 17 participants whom the researcher met before while doing research in the US. Hence, the participants gave their intimate and objective views, thoughts and experiences. These online interviews also allowed him to have understandings of the meanings and give an opportunity to search for further information and future research. For this purpose, the researcher also obtained reflections from the ones who taught listening-speaking course at the end of the class and collected the syllabi in order to compare and contrast with the other findings derived from the tools. The rationale behind the listening- speaking course choosing a reflection tool was that the productive skills, in particular speaking, is always critical and has gained much importance in the last decades. In addition to this, the researcher himself observed some of the classes as an audit and took some notes regarding the lecturers' teaching methods and teaching materials during the class. The classroom observation method in this study was to collect data about teaching methods and teaching materials during ELT language courses. 5 English language courses were observed over a period of 4 weeks. During the study, the researcher used direct observation which involves the presence of the observer and should be placed in the back of the classroom in order not to disturb the 
lesson (Drury, 1992). According to Patton (1990), there are three kinds of observation; highly-structured observation (the researcher knows what to do in advance while collecting data), semi-structured observation (the researcher has a list in hand but with a less systematic order) and unstructured observation (the researcher is not so sure what he is looking for during the observation). In the current study, the researcher used highly structured observation which means sitting passively in the classroom and attended the classes knowing what to do and took some notes about the lecturers' teaching approach and teaching materials.

\section{Data Analysis}

In accordance with the research questions, some key words such as teaching methods/approaches, teaching materials and views about the current language teaching system, were determined to analyze the content properly.

In the first step of analyzing the data, the researcher listened to the recordings several times to obtain a general sense of the content. In the second place, the researcher coded the data and divided them into segments with some keywords, as mentioned above, and examined them in detail. According to Grbich (2013), codifying means arranging things systematically in order to make something part of a system / classification, finally to categorize. Another researcher, Saldana (2015) states that "coding enables you to organize and group similarly coded data into categories or 'families' because they share some characteristic" (p. 10). In data analysis, the researcher tried to look at main themes regarding the research questions of the study such as; methods, approaches, teaching, materials, classroom, syllabuses, learners and education system. As noted above, the reason why three instruments were used in the current study was to compare and contrast the data regarding the internal validity, that is triangulation.

\section{FINDINGS}

The findings regarding two settings will be discussed separately, considering lecturers' views on language teaching methods, teaching materials and the US second language teaching system. The findings were presented under the subsections 'Setting $A$ ' and 'Setting B' (views on second language teaching methods and teaching materials).

\section{Setting A}

In relation to the first research question, the lecturers in the university mentioned that they use Communicative Language Teaching Approach (CLT) in their classes and they refer to the importance of productive skills rather than receptive skills. Some remarks made by one participant are as follows:

We're using communicative teaching approach by the textbook and skill-based with the exception of technology, there are a lot of technologies. In reality, when we communicate we listen and speak so that's what I do.

They try to teach grammar implicitly within the context. One of the participants made the following remarks:

We teach them grammar every single day, not sometimes in the explicit way that they want with a grammatical terminology, but we teach them implicitly. They learn that by communication.

They have some courses such as Academic Writing, Academic Reading and Creative and Critical Thinking. They stated that language teaching should be in harmony with the culture. In relation to the culture, one participant made a remark:

You can never separate the spoken language from the unspoken language, the culture itself behind, real-life context. I want them to be proficient in the target language.

The views about the second research question are really interesting in that they prepare their own teaching materials for per semester and year, but they revise it continuously in line with the learners' needs.

Each one of us prepares a syllabus and universities are free to create whatever they want. What we all have the standards and we all keep in mind those standards. 
I prepare all of our documents, materials and rubrics. I make them all. We have just one general template showing basic information and then we fill in the specific information for each course. We also work together to create our curriculum, so we didn't take anyone else's curriculum. And then we have a revision process that we go through to revise the curriculum every section.

Some of the lecturers stated that they don't have any standard curriculum for all language teaching classes but they can have Cambridge Academic Groups system in the university in the near future by adding that they really need a kind of standard language teaching system. Anyway, as the institutions are independent from each other, the coordinating position is mainly based on the Language Center in the university. The directors of Language Center claimed that they prepare the teaching materials and they are so satisfied with the result, that is 'success'.

As for the third research question, some of the lecturers are so satisfied with their second language teaching system whereas some of them stated that they should change the way and they should adopt a kind of standard system in which everybody is involved in such as using the same syllabus and test. However, all of them are so happy to prepare their own materials, and they put emphasis on insistently the importance of the culture, real life contexts and learner-based activities. They also added that while teaching a language, the target language should be used properly without any code-switching.

\section{Setting B}

The respondents' answers to the first research question regarding the method in ELT classrooms are inquiry based teaching method, which is learner-centered rather than teacher-centered and it enables students to improve their critical thinking skills and prepare projects based on real-life contexts. They generally claim that the courses based on inquiry are more successful than the others which are mainly inclined to traditional activities.

Some of the remarks made by the participants are as follows:

I do a lot of different things in the class. I apply inquiry-based teaching which is very flexible. I want the students to come up with different ideas and things. The goal has become to get them to show their critical thinking which is also related to inquiry.

I use either like a video or going online and just get them start thinking of something. I teach inquiry and how to use the language properly. It's a kind of learner-centered approach. Teaching something with a lot of doing projects, you can give the students support may be in grammar may be in writing may be in speaking but they use all those skills to do some kind of projects.

The materials we give the students are primarily created by the teachers.

The second research question is about the teaching materials. All of the lecturer/instructors responded that they prepare their own materials to use and benefit from quite a few books just as a resource. The participants made the remarks as below:

I have textbooks and I use it as a resource, I always create and bring original materials as possible. I provide them with the input with the varieties of language use. I do spend a lot of time looking for authentic materials.

I combine the textbooks with authentic materials. Then I go online, use newspapers I use radio podcasts, YouTube videos, shortened TV shows, that's the integration of the reality what the textbook already has and we need to give them more.

They also change and revise the syllabuses in accordance with the learners' needs. For example, one participant stated:

I always revise and update the syllabuses to meet the learners' needs.

They have just four courses such as Reading-Writing, Listening-Speaking, Language Analysis and Inquiry. They prepare all syllabuses for four levels; intermediate, high-intermediate, advanced and academic. It can be said that skill based teaching rather than integrated are applied in this language center except only for 
inquiry course, which enables the students to improve all four skills by using their critical thinking skills. They also use the Michigan Placement Test at the beginning of the semester; if the students have already score from the accredited exams, they don't need to take this test. There aren't any quizzes, visas or final exam. The students' language proficiency is determined by looking at their projects, portfolios and full year performances. There are some levels showing their levels such as $A, B, B-, B+, C, C-, D$, D-. If the students can't have A-B for graduate level, they fail. However, they can be successful even if they have $C$ for undergraduate students.

As for final research question, the participants claim that they are so satisfied with student learning outcomes at the end of the year. They compared their success with the previous teaching methods, which is totally dependent on the course books. They also claimed that students are also very happy to be active in the classroom and to use their capacity.

\section{Reflections and Classroom Observations}

As noted above, the researcher obtained reflections from the lecturers who taught listening-speaking course and collected syllabuses. These reflections provided some important insights about the teaching methods and teaching materials about the courses, in which it proved that the lecturers' remarks in the online interviews are really compatible with these syllabuses.

Apart from the reflections, taking the classes as an audit was also a good platform for observing the classroom dynamics, learners' attitudes and activities used and applied by the lecturer. This access enabled the researcher to look at the attitudes and course flow closely. Thus, the researcher had the chance to observe the lecturer and learner responses and reactions during the course as well. To be brief, the classroom observations provided the researcher examples of aspects of the course about how it proceeds.

Finally, the researcher, by keeping the general keywords about the research in mind, took some notes about teaching approach and teaching materials in order to compare and contrast with what the participants said in online interviews.

The next section gives the suggestions, discussion and conclusion of the research.

\section{DISCUSSION and CONCLUSION}

After analyzing the results, three main suggestions can be made for ELT teachers/lecturers, professors and academics and language policy makers.

Firstly, teachers can take advantage of being aware of using as much possible as a real language. It is also crucial for them to bring the students more cultural input and offer them movies and books that can be discussed in real-life possibilities in which Communicative Language Teaching (CLT) puts much of the emphasis on the need for authentic objects or texts to provide authenticity to the communicative situation and medium. In relation to this, Brinton (2009) stated that "non-native speakers (both inside the classroom and outside the classroom) make use of the here and now objects in the immediate environments" (p. 459). Similarly, Snelson and Perkins (2009) stated that YouTube provides teachers with special features to obtain several videos together in a playlist and to prepare the concepts and topics of the lessons, thereby enabling them find videos from real-life, that is authentic.

Secondly, it is also valuable that teachers try to engage students in real-life conversation. We also shouldn't stop the students when they are making mistakes to correct them. Based on the assumption that speaking is one of the most problematic aspects in a second language learning situation (Ellis, 1994; Horwitz et al., 1986; Young, 1991), it is also critical for the students to speak in a safe environment without any risk. In order to do this, it is recommended that instructors provide topics that interest students, or provide opportunities for students to select and arrange projects.

Lastly, it is crucial for teachers to drop the native language or drop that to the minimum possible. Teachers need to give up code-switching for example, from English to Turkish or vice versa. In general terms, Greer (2007) described code-switching as "situations in which bilingual people alternate between languages, 
either between or within utterance" (p. 27). At the beginning of the learning process, it can be said that it is not totally omitted. As Rios and Campos (2013) stated that code-switching should not be encouraged by teachers, but it should also not be severely punished in the first stages of the learning process. This is one of the striking points; if you teach a foreign language, you have to speak that target language and provide the students with lots of culturally-based and authentic materials, that is, comprehensible input.

In conclusion, it can be widely acknowledged that language policies and needs can be different from each other. It can also be futile to expect that there is a common framework or system which is suitable for each country and institution. The results of the research can be outlined as follows: The insights provided from two universities can be in line with the eclectic methods, which is one of the 21st century skills. According to Larsen-Freeman (2000), "when teachers, who subscribe to the pluralistic view of methods, pick and choose from among methods to create their own blend, their practice is said to be eclectic" (p. 183). In the light of the data, it can be concluded that two universities in the US focus on the learners' needs and prepare their teaching and curriculum materials on their own and they would like to integrate authentic materials into the classrooms. As Khansir and Pakdel (2014) stated that "analysis of language learners' needs is seen as the first step towards preparation of language course" (p. 1). Looking at the courses in particular, they are not in linear with mostly adapted course books, only used as reference books, which is really striking point of the result enabling the instructors and lecturers revise the curriculum continually. It can be suggested that School of Foreign Languages (SFL) should pay attention to the importance of the needs analysis of the learners and they should give up the dependency to the course books. Thus, the instructors working in SFL are always conducive to prepare and revise the materials and curriculum in accordance with the learners' needs.

In relation to the limitations, this study was restricted to 17 ELT lecturers/instructors working in two different universities within US higher education system. Moreover, the scope of the study was limited to the qualitative data gathered from online semi-structured interviews, reflections and classroom observations. In short, this study has some limitations regarding the factors noted above. Thus, further research is also necessary for getting an intensive and comprehensive view about second language teaching methods in US higher education system.

\section{REFERENCES}

Briguglio, C. \& Watson, E. (2014). Embedding English language across the curriculum in higher education: A continuum of development support. Australian Journal of Language and Literacy, 37(1), 68-74.

Brinton, D.M. (2001) The use of media in language teaching. In Celce-Murcia, M. (ed.) Teaching English as a second or foreign language (3rd ed., pp.459-475). Boston: Heinle and Heinle.

Coleman, J. A. (2006). English-medium teaching in European higher education. Language Teaching, 39, 114.

Creswell, J. W. (1998). Qualitative inquiry and research design: Choosing among five traditions. Thousaland Oaks, CA: Sage.

Creswell, J. W. \& Miller, D. L. (2000). Determining validity in qualitative inquiry. Theory into Practice, 39(3), 124-131.

Devlin, M., \& Samarawickrema, G. (2010). The criteria of effective teaching in changing higher education context. Higher Education Research \& Development, 29(2), 111-124.

Drury, C.G., 1992. Methods for direct observation of performance. In Wilson, J.R. \& Corlett, E.N. (Eds) Evaluation of human work, London: Taylor \& Francis.

Eaton, S.E. (2010). Global Trends in Language Learning in the Twenty-first Century. Calgary: Onate Press.

Ellis, R. (1994). The study of second language acquisition. Oxford: Oxford University Press.

Giri, D.R. (2016). Project-based learning as $21^{\text {st }}$ century teaching approach: A Study in Nepalese Private Schools. US-China Education Review, 6(8), 487-497.

Grbich, C. (2013). Qualitative data analysis: An introduction. $2^{\text {nd }}$ Edition. Sage.

Greer, T. (2007). Accomplishing identity in bilingual interaction: Codeswitching practices among a group of multiethnic Japanese teenagers. Unpublished Ph.D. University of Southern Queesnland Australia.

Hannan, A., \& Silver, H. (2000). Innovating in higher education: Teaching, learning and institutional cultures. Buckingham: Open University Press.

Horwitz, E. K., Horwitz, M. B., \& Cope, J. A. (1986). Foreign language classroom anxiety. Modern Language Journal, 70, 125-132. 
Hu, G., \& Lei, J. (2014). English-medium instruction in Chinese higher education: A case study. High Educ, 67:551-567.

Karn, S. K. (2007). Current trends in ELT around the globe. Journal of Nepal English Language Teachers' Association (NELTA), $12(1$ \& 2), 60-66.

Kelly, T and Minges, M (2012) Maximizing mobile, information and communications for development. The World Bank. Available online at: www.worldbank.org/ict/IC4D2012

Khansir, A. A., \& Pakdel, F. (2014). Needs Analysis and Language Teaching. Language in India, 14(3), 1-20.

Larsen-Freeman, D. (2000). Techniques and Principles in Language Teaching. Oxford: Oxford University Press.

Moughamian, A.C., Rivera, M.O., \& Francis, D.J. (2009). Instructional models and strategies for teaching English language learners. Portsmouth, $\mathrm{NH}$ : RMC Research Corporation, Center on Instruction.

Patton, M. Q. (1990). Qualitative Evaluation and Research Methods. London: Sage.

Richards J. C. \& Rodgers, T. S. (2003). Approaches and methods in language teaching, 2nd edition, Cambridge: Cambridge University Press.

Rios, J., \& Campos, J. L. E. (2013). Code-Switching in the EFL classroom: Friend or foe? Revista De Lenguas Modernas, 19, 375-391.

Roulston, K. (2010). Considering quality in qualitative interviewing. Qualitative Research, 10(2), 199-228.

Saldaña, J. (2015). The coding manual for qualitative researchers. Sage.

Slavin, R. E., \& Cheung, A. (2005). A synthesis of research on language of reading instruction for English language learners. Review of Educational Research, 75(2), 247-284.

Yin, R. K. (2003). Case study research: Design and methods (3 $3^{\text {rd }}$ ed.). Thousand Oaks, CA: Sage.

Young, D. J. (1991). Creating a low-anxiety classroom environment: What does language anxiety research suggest? Modern Language Journal, 75, 426-439.

\section{Correspondence}

Assist. Prof. Dr. Ceyhun YÜKSELIR

ceyhunyukselir@gmail.com

ceyhunyukselir@osmaniye.edu.tr 